\title{
Influence of Thermocycling and Sealer Coating Application on Shore Hardness of Soft Denture Lining Material
}

\author{
Ismet Danial Nasution, Haslinda Z. Tamin, Ariyani Ariyani, Ivana Ivana* \\ Department of Prosthodontic, Faculty of Dentistry, Universitas Sumatera Utara, Medan 20155, Indonesia
}

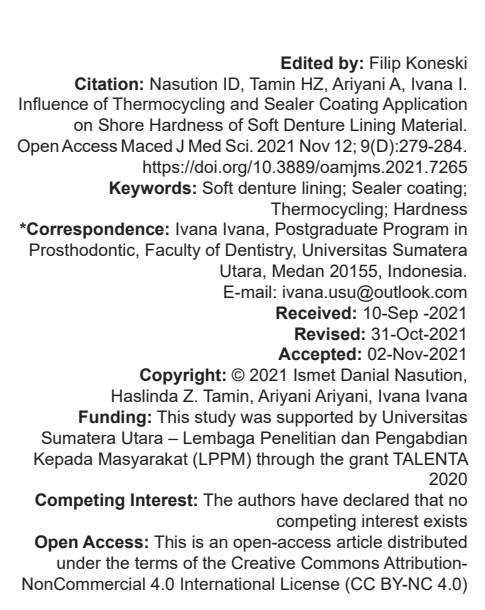

\section{Introduction}

One of the treatment choices to increasing mastication, phonetics, and esthetics function in edentulous patient is fabrication of removable denture [1], [2]. Some cases particularly in atrophic ridge, thin and non-resilient mucosa, bony undercut, single denture, congenital or acquired defect, patients may encounter some functional problems such as persistent pain, inability to chew, instability, and poor retention of the denture [1], [2], [3]. Differences between modulus of elasticity of acrylics denture base approximately $2400 \mathrm{MPa}$ higher than mucosa in physiological rest condition that is about $1.25-5$ $\mathrm{MPa}$, so when there is local stress concentrated on denture bearing mucosa or denture with poor stability, trauma or ulceration can occurred [4]. To overcome this problem, soft denture lining (SDL) materials can be used [1], [2], [3]. SDL with resiliency similar to that of oral mucosa can give cushion effect by preventing local stress concentration and distributing an uniform functional load on denture-bearing mucosa, therefore minimizing trauma [4], [5], [6]. The clinical effectiveness of SDL has been widely reported in the previous studies. In a 6-year retrospective study, 93\% of edentulous patients felt more comfortable using dentures with SDL [7]. Other studies have also shown that the use of SDL on the mandible can improve masticatory function and create higher bite pressure without any side effects on muscle activity, thereby increasing patient satisfaction [5], [8]. 
Based on their chemical composition, SDL materials can be divided into two categories, namely, resin acrylic-based SDL and silicone-based SDL. Acrylic-based SDL consists of powders containing acrylic polymers and copolymers and liquid containing acrylic monomers and plasticizers (ethyl alcohol and/ or ethyl acetate) which maintain the resilience of the material. Silicone-based SDL material consists of polydimethylsiloxane and does not contain plasticizers. The resilience property of the silicone-based SDL is obtained from the cross-linked structure of the polymeric siloxane chain [6], [9], [10], [11]. Silicone-based SDL has better viscoelastic properties with lower permanent deformation but this material is less resilient than acrylic SDL, and this may affect patient comfort and the ability of the material to absorb mastication loads [6].

Aging can affect the physical properties of a material, one of which is the hardness of SDL. The aging process also causes this material to become porous, thereby reducing the ability of the material as a shock absorbant. The change in hardness/loss of softness in SDL acrylic material is caused by an aging process that occurs in three stages: Loss of ethanol, loss of plasticizer, and water sorption. This causes the SDL material to become harder and stiffer, which affects the surface integrity and viscoelasticity of the material, therefore giving a negative effect on the tissue [9], [12], [13].

One of the methods for simulation of the aging process is thermocycling. Thermocycling consists of cycle of immersing specimens in a water bath containing distilled water with a temperature of $5^{\circ} \mathrm{C}$ and $55^{\circ} \mathrm{C}$ with $60 \mathrm{~s}$ dwell time. Although there is no reference to how many cycles to do on SDL material, it can refer to the number of meals 3 times a day so that it is estimated that a person experiences 3 times a day of thermal shock. Temperature variations are selected based on the temperature of the food that is swallowed while eating and does not damage the oral cavity tissue [6], [14].

Mancuso et al. demonstrated that thermocycling could increase the hardness and cause discoloration in both the acrylic-based SDL group and the siliconebased SDL group. However, the increase in hardness was greater in the acrylic-based SDL group than in the silicone-based SDL group [13]. Thermocycling on silicone-based SDL also causes an increase in the hardness of the material. This is due to the composition of the silicone material and the increased water sorption. Goiato et al. showed that thermocycling did not significantly affect the water sorption of siliconebased SDL materials, but there was a statistically significant increase in the hardness of silicone-based SDL materials after thermocycling [15].

To extend the duration of SDL usage, sealer coating was developed to protect the material against external environmental stress caused by mechanical and chemical factors [9]. Sealer coating is a traditional material that is usually used on tooth surfaces and restorative materials to coat surface imperfections and seal gaps, fissures, and material porosity [16]. Sealer coating protects SDL materials by acting as mechanical barrier to prevent water sorption and the solubility of chemical components associated with accelerated degradation of materials, thus maintaining softness and reduces surface roughness and material porosity [3], [9]. Some materials that can be used as sealer coatings are monopoly, varnish, Palaseal, Kreguard, and Permaseal fluorinated copolymer coatings. Monopoly is a polymethyl methacrylate syrup made from clear polymer powder mixed with heat polymerizing acrylic monomer in a ratio of 1:10 [17], [18].

Malmstorm et al. showed that the application of a coating material with Permaseal and Monopoly can significantly maintain the soft properties of the material. Permaseal coatings retain their soft properties better than other groups [17]. However, this contradicts with Edabian et al. study that showed the hardness of the material will increased along the time and the application of sealer coating with monopoly cannot maintain the properties of the material [19].

The effect of sealer coating seems to be influenced by time. In clinical use with functional temperature fluctuations in the oral cavity, the sealer coating is expected to provide protection against aging of SDL materials [9]. Research has also shown that the thermocycling simulation increases the hardness of the material and the sealer coating has a positive effect on protecting the hardness properties of both siliconebased and acrylic-based SDL materials. Sealer coating prevents the penetration of other agents from the outside environment. Researchers also recommend the use of a sealer coating material even though it is not provided by the manufacturer [20]. This is also in accordance with the previous studies which showed coated SDL materials and followed by thermocycling can maintain SDL material properties compared to the uncoated group [12]. Another study also showed that thermocycling had a more significant effect on material properties in the acrylic-based SDL group but the sealer coating effect was more significant in the silicone-based SDL group when thermocycled [6].

The purpose of this study was to determine the effect of thermocycling and sealer coating on the shore hardness of the acrylic-based and silicone-based autopolymerizing soft denture lining materials.

\section{Materials and Methods}

In this study, according to Federer's formula, the sample size in each group was five samples. The total samples made in this study were 40 samples, which 20 samples were made of acrylic-based 
auto-polymerizing SDL (Durabase Soft, Reliance Dental Manufacturing LLC, Illinois, USA) and 20 samples were made of silicone-based auto-polymerizing SDL (Mollosil, Detax GmbH, Ettlingen, Germany). Monopoly was used as sealer coating for acrylic-based auto-polymerizing SDL. Monopoly was made mixing clear auto-polymerizing polymer powder with heat polymerizing acrylic monomer in a ratio of $1: 10$, heated in a water bath at $55^{\circ} \mathrm{C}$, and stirred until thickened for $8 \mathrm{~min}$. For the silicone-based auto-polymerizing SDL groups, we used varnish (Lustrol, Detax $\mathrm{GmbH}$, Ettlingen, Germany) which is the material available from the manufacture (Figure 1). The samples were divided into eight groups $(n=5)$, namely, the uncoated and nonthermocycling acrylic-based auto-polymerizing SDL, the coated and non-thermocycling acrylic-based autopolymerizing SDL, the uncoated and thermocycling acrylic-based auto-polymerizing SDL, the coated and thermocycling acrylic-based auto-polymerizing SDL, the uncoated and non-thermocycling silicone-based autopolymerizing SDL, the coated and non-thermocycling silicone-based auto-polymerizing SDL, the uncoated and thermocycling silicone-based auto-polymerizing SDL, and the coated and thermocycling silicone-based auto-polymerizing SDL.

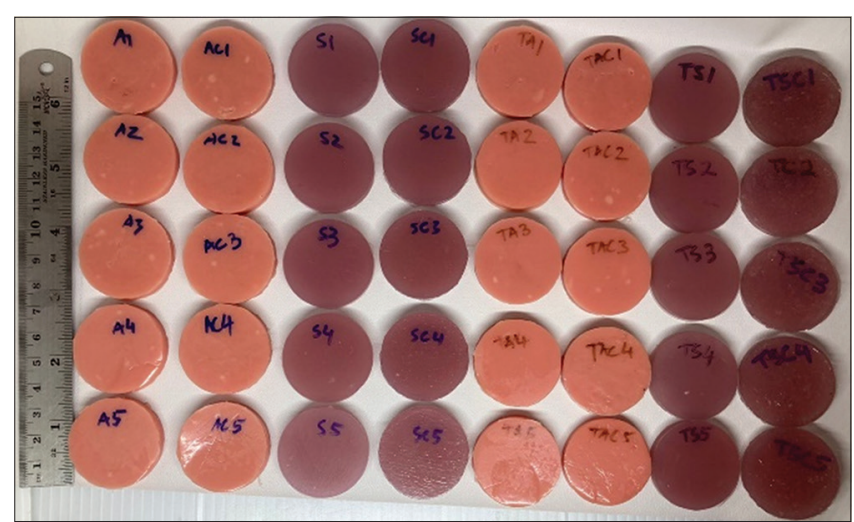

Figure 1: A total of 40 samples into eight treatment groups: The uncoated and non-thermocycling acrylic-based auto-polymerizing $S D L$, the coated and non-thermocycling acrylic-based autopolymerizing $S D L$, the uncoated and thermocycling acrylic-based auto-polymerizing SDL, the coated and thermocycling acrylicbased auto-polymerizing SDL, the uncoated and non-thermocycling silicone-based auto-polymerizing SDL, the coated and nonthermocycling silicone-based auto-polymerizing $S D L$, the uncoated and thermocycling silicone-based auto-polymerizing $S D L$, and the coated and thermocycling silicone-based auto-polymerizing SDL
SDL samples were made in accordance with the manufacturer's instructions, poured into disc-shaped stainless steel mold with a diameter of $35 \mathrm{~mm}$ and thickness of $6 \mathrm{~mm}$ for hardness testing samples according to the International Organization for Standardization (ISO) standards ISO 10139-2: 2016 for long-term resilient denture liner (Figure 2). The mold was closed and waited 20 min for the complete polymerization of the material according to the manufacturer's instructions. The sample was then removed from the mold. For the coated group, sealer coating was applied using a brush, evenly in one direction motion and then allowed to dry for $5 \mathrm{~min}$ in the air. After drying, it was recoated in the same way 3 times (Figure 3 ).

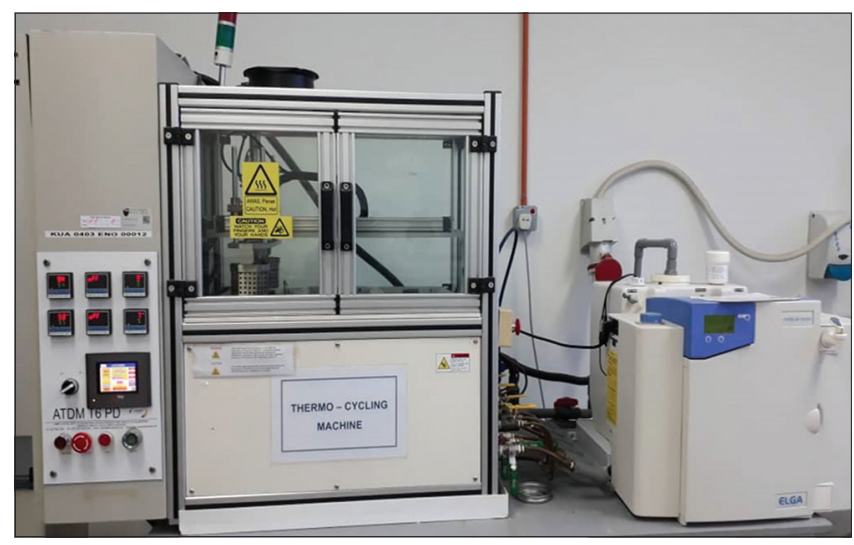

Figure 3: Thermocycling groups was put into the thermocycling machine and 2000 cycles with a temperature $5-55^{\circ} \mathrm{C}$ with $60 \mathrm{~s}$ dwell time (for 2 years simulation) were performed

For the sample group without thermocycling, the sample was put in an incubator at $37^{\circ} \mathrm{C}$ for $24 \pm 1 \mathrm{~h}$ before testing. For the sample group with thermocycling, the sample was put into the thermocycling machine (Figure 4). Thermocycling was carried out for 2000 cycles with a temperature $5-55^{\circ} \mathrm{C}$ with 60 seconds dwell time (for 2 years simulation), then, the sample was removed from the thermocycling machine and then tested. For hardness testing, the sample was placed on a solid and flat place on the durometer table. The shore A durometer (Kori KR14 A, Japan) was calibrated in advance according to ASTM D2240 and the hardness test was recorded in shore units. Each shore unit represents $0.0254 \mathrm{~mm}$ deflection by the durometer indenter. The tip of the durometer indenter which is a truncated cone with a length of $2.5 \mathrm{~mm}$ and using an $822 \mathrm{~g}$ spring, it is placed on the sample slowly until the sample's surface
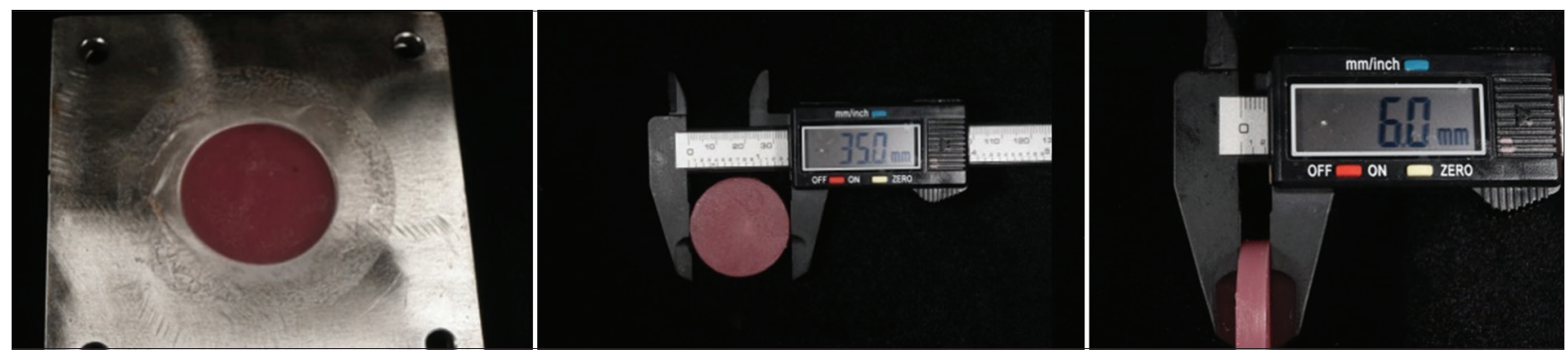

Figure 2: Sample was made and then poured into disc-shaped stainless steel mold with diameter $35 \mathrm{~mm}$ and thickness $6 \mathrm{~mm}$ 


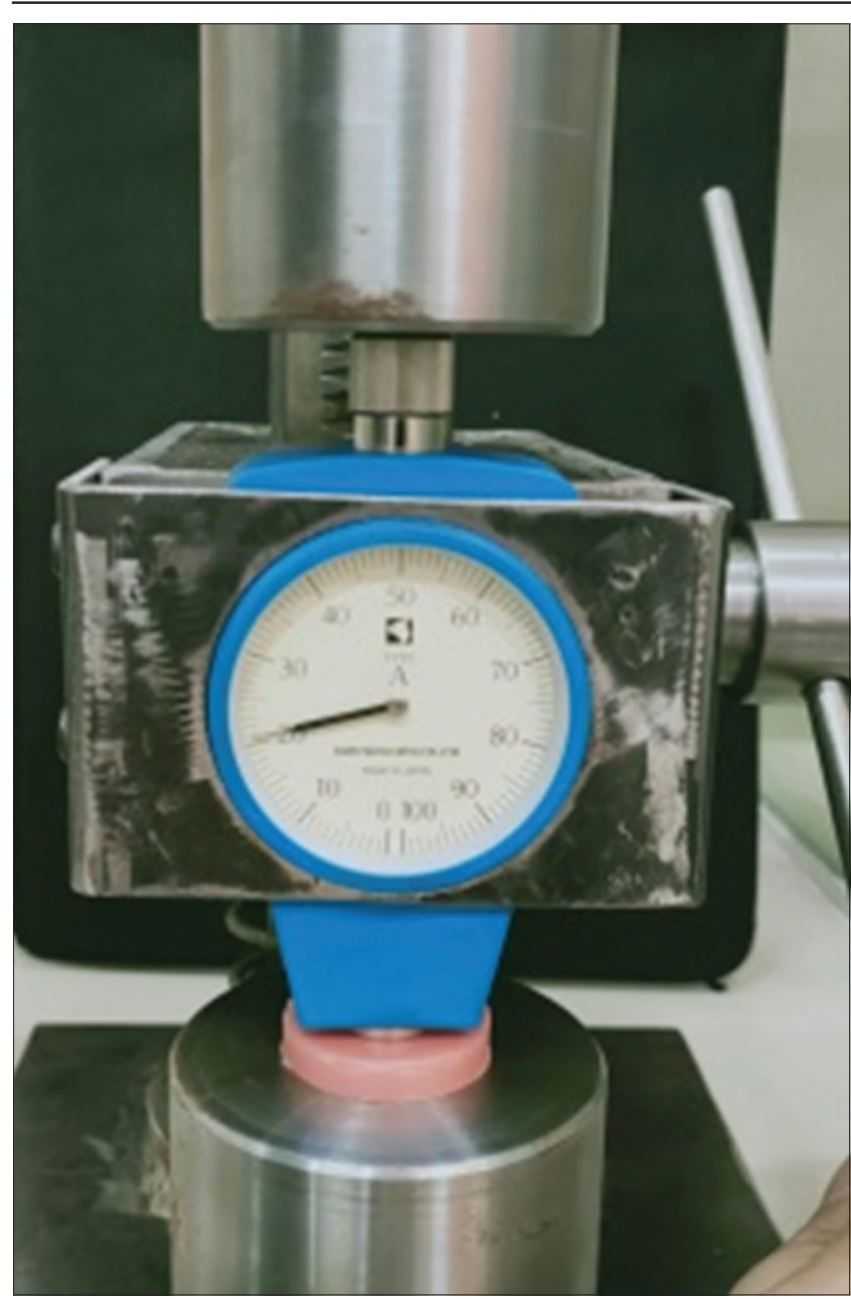

Figure 4: Shore hardness test using shore A durometer (Kori KR14 A, Japan) was carried out at 5 points for each sample. From five measurements, the mean value of shore hardness was calculated for one sample

and the contact surface of the durometer forms one plane and the reading of the hardness value was carried out $5 \mathrm{~s}$ after the load was given. Shore hardness test was carried out at 5 points for each sample. The loading points must be evenly distributed on the surface and at least $12 \mathrm{~mm}$ from the edge of the sample. From five measurements, the mean value of shore hardness was calculated for one sample.

\section{Results}

Mean and standard deviation for shore hardness testing is shown in Figure 5. To determine the effect of sealer coating on the hardness of SDL materials, the data were tested by t-test. Before t-test was conducted, all data were tested by Shapiro-Wilk and it was found that the data in this study were normally distributed. T-test result between the uncoated and non-thermocycling acrylic-based group and the coated and non-thermocycling acrylic-based group obtained $p$

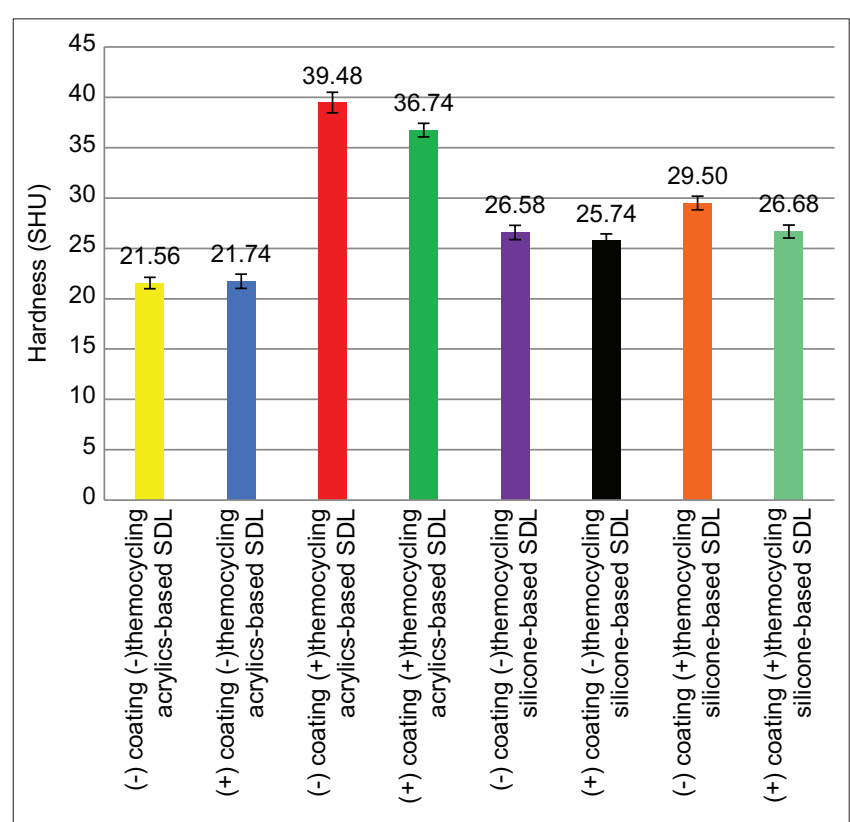

Figure 5: Average hardness value of soft denture lining acrylic and auto-polymerizing silicone

value $=0.696$. This shows that there is no effect of using sealer coating on the hardness of non-thermocycling acrylic-based SDL. T-test results between the uncoated and thermocycling acrylic-based groups with coated and thermocycling acrylic-based group obtained a significance value $p=0.001$. This shows that there is an effect of using sealer coating on the hardness of thermocycling acrylic-based SDL. For the silicone group T-test results between the uncoated and nonthermocycling silicone-based groups with coated and non-thermocycling silicone-based group obtained a significance of $p=0.096$, which means that there is no effect of the use of sealer coating on the hardness of non-thermocycling silicone-based group. The results of the t-test between uncoated and thermocycling siliconebased group with coated and thermocycling siliconebased group showed a significance of $p=0.001$. This shows that there is an effect of using sealer on the hardness of thermocycling silicone-based SDL.

To determine the effect of thermocycling on the hardness of SDL materials, the data were tested with t-test. t-test between the uncoated and non-thermocycling acrylic-based groups with the uncoated and thermocycling acrylic-based group obtained $p=0.001$, indicating that there was an effect of thermocycling on the hardness of the uncoated acrylic-based SDL group. T-test between the coated and non-thermocycling acrylic-based group with the coated and thermocycling acrylic-based group showed $p=0.001$. This shows that there is an effect of thermocycling on the hardness of the acrylic-based SDL group with sealer coating. T-test results between the uncoated and non-thermocycling silicone-based group with the uncoated and thermocycling siliconebased groups obtained significance $p$ value $=0.001$. This indicates that there is an effect of thermocycling 
on the hardness of the SDL uncoated silicon-based SDL group. T-test results between the coated and nonthermocycling acrylic-based groups with the coated and thermocycling silicone-based group significance obtained were $p=0.057$. This shows that there is no effect of thermocycling on the hardness of the coated silicone-based SDL group.

\section{Discussion}

All groups in this study have an average shore hardness value that follows ISO 10139-2: 2016 standard which classifies SDL materials into two types, namely, soft type and extra soft type. The shore A hardness value after $24 \mathrm{~h}$ of immersion in distilled water at $37^{\circ} \mathrm{C}$ for soft types is $25-50$ shore hardness and for extra soft types below 25 shore hardness.

In this study, in both the non-thermocycling acrylic-based and silicone-based groups, the results of the t-test showed no significant difference between the coated and non-coated groups. This is probably because the immersion is carried out for only $24 \mathrm{~h}$ so that the sealer coating might not show its effect as a barrier to prevent other agents from the surrounding environment enters the material. This study also showed that there was a significant difference between the coated and the uncoated acrylic-based group with thermocycling. The results of this study are in accordance with the previous study by Gronet (1997) that showed coating the SDL material using Palaseal or monopoly was able to significantly increase the resilience of the material compared to the group that was uncoated [12]. The results of the t-test for the coated and uncoated silicone-based group followed by thermocycling showed that there was an effect of using sealer coating on preserving the hardness of siliconebased SDL groups. The results of this study indicate that the use of sealer coating is able to maintain the hardness properties of silicone-based SDL material against aging. Histrov et al. (2017) showed that sealer coating had a positive effect on maintaining the hardness properties of both acrylic-based and siliconebased SDL groups by preventing the entry of agents from the surrounding environment into the material [20].

T-test result in this study indicates that there is a significant effect of thermocycling on shore hardness in the uncoated acrylic-based SDL group and also the t-test results showed significant effect of thermocycling on shore hardness in the coated acrylicbased SDL group. The results of this study indicate that thermocycling increase the hardness of acrylicbased SDL materials similar to the previous studies. Hekimoglu and Anil (1999) observed that thermocycling can accelerate the increase in hardness of acrylicbased SDL materials and the solubility of the materials.
Thermocycling increases the plasticizer leached out from the material. Hardness changes occur in three stages in the same time, namely, loss of plasticizer, loss of ethanol, and water sorption. Loss of plasticizer causes the material to become stiffer and increases the mean shore hardness of the acrylic-based SDL material [14].

In this study, the result also indicates the effect of thermocycling on shore hardness in the uncoated silicone-based SDL group. In contrary, the T-test between the coated and non-thermocycling silicone-based SDL groups with coated and thermocycling silicone-based SDL group showed no significant different on shore hardness. This shows that the application of sealer coating on the silicone-based SDL group can maintain the hardness properties of the material against aging. This is in accordance with da Silva et al. study (2010) that showed that the silicone-based SDL material has better dimensional stability than acrylic-based SDL even after thermocycling was performed and the effect of the sealer coating was more significant on silicone-based SDL [6].

This study also showed that changes in hardness were greater in the acrylic-based SDL group than the silicone-based SDL group. Mancuso et al. (2010) showed that thermocycling can increase hardness, water absorption, and cause color changes in both the acrylic-based SDL and the silicone-based SDL groups. However, the increase in hardness and water sorption was greater in the acrylic-based SDL group compared to the silicone-based SDL group. This is due to the solubility of the plasticizer contained in the acrylic-based SDL material causes greater water sorption, and as the result, the hardness increases and the color changes [13]. Kiat-Amnuay et al. study (2005) showed that the auto-polymerizing acrylic-based SDL material is the softest material at the beginning of the study but this material became harder after being stored in water for 1 year and this process of change in hardness was more significant observed in the group that was uncoated [21].

\section{Conclusion}

Based on the research results, it can be concluded that the use of sealer coating can maintain the hardness properties of both the acrylic-based and silicone-based self-polymerizing SDL materials, thus increasing the durability of SDL materials. However, the effect of sealer coating in protecting the hardness of SDL materials against aging was more prominent in the silicone-based SDL group. Thermocycling increases the hardness of both in the acrylic-based and siliconebased SDL group and this change is greater in the acrylic-based SDL group. Although there are limitations to this study, it can be recommended to apply sealer 
coating on both acrylic-based and silicone-based SDL materials to maintain the physical properties of the material and extend the service life of SDL materials.

\section{Acknowledgment}

The authors would like to acknowledge Universitas Sumatera Utara - Lembaga Penelitian dan Pengabdian Kepada Masyarakat (LPPM) for this research funded by TALENTA 2020. The authors also would like to give special thanks to Mrs. Helen $\mathrm{Ng}$ and Biomaterial Research Laboratory at Universiti Malaya for assistance in performing thermocycling of the samples.

\section{References}

1. Pisani MX, Segundo AL, Leite VM, de Souza RF, da Silva MA, da Silva $\mathrm{CH}$. Electromyography of masticatory muscles after denture relining with soft and hard denture liners. J Oral Sci. 2013;55(3):217-24. https://doi.org/10.2334/josnusd.55.217 PMid:24042588

2. Palla ES, Karaoglani E, Naka O, Anastassiadou V Soft denture liners' effect on the masticatory function in patients wearing complete dentures: A systematic review. J Dent. 2015;43(12):1403-10. https://doi.org/10.1016/j. jdent.2015.09.005

PMid:26404406

3. Kutlu IU, Yanikoğlu ND, Kul E, Duymuş ZY, Sağsöz NP. Effect of sealer coating and storage methods on the surface roughness of soft liners. J Prosthet Dent. 2016;115(3):371-6. https://doi. org/10.1016/j.prosdent.2015.10.004

PMid:26723099

4. Kim BJ, Yang HS, Chun MG, Park YJ. Shore hardness and tensile bond strength of long-term soft denture lining materials. J Prosthet Dent. 2014;112(5):1289-97. https://doi.org/10.1016/j. prosdent.2014.04.018

PMid:24882597

5. Ogawa A, Kimoto S, Saeki H, Ono M, Furuse N, Kawai $Y$ The influence of patient characteristics on acrylic-based resilient denture liners embedded in maxillary complete dentures. J Prosthodont Res. 2016:60(3):199-205. https://doi. org/10.1016/j.jpor.2015.12.001

PMid:26778580

6. Da Silva J, Takahashi J, Nuňez J, Consani R, Mesquita M. Effect of accelerated aging and surface sealing on the permanent deformation of auto-polymerising soft linings. Gerodontology. 2010;29(3):188-93. https://doi. org/10.1111/j.1741-2358.2010.00419.x

PMid:20825497

7. Murata H, Hamada T, Sadamori S. Relationship between viscoelastic properties of soft denture liners and clinical efficacy. Jpn Dent Sci Rev. 2008;44:128-32. https://doi.org/10.1016/j. jdsr.2008.06.001

8. Kimoto S, Yamamoto S, Shinomiya M, Kawai Y. Randomized controlled trial to investigate how acrylic-based resilient liner affects on masticatory ability of complete denture wearers. J Oral Rehabil. 2010;37(7):553-9. https://doi. org/10.1111/j.1365-2842.2010.02070.x

PMid:20202095

9. Dayrell A, Takahashi J, Valverde G, Consani R, Ambrosano G, Mesquita M. Effect of sealer coating on mechanical and physical properties of permanent soft lining materials. Gerodontology. 2012;29(2):e401-7. https://doi. org/10.1111/j.1741-2358.2011.00487.x

PMid:21535103

10. Rodrigues S, Shenoy V, Shetty T. Resilient liners: A review. J. Indian Prosthodont Soc. 2013;13(3):155-64.

PMid:24431729

11. Jabbal R, Datta K. Comparative evaluation of water sorption and solubility of two autopolymerizing soft denture liners in distilled water and artificial saliva. Indian J Dent Sci. 2016;8:208. https:// doi.org/10.4103/0976-4003.196811

12. GronetPM, Driscoll CF, Hondrum SO. Resiliency of surface-sealed temporary soft denture liners. J Prosthet Dent. 1997;77(4):370-4. https://doi.org/10.1016/s0022-3913(97)70161-6 PMid:9104713

13. Mancuso DN, Goiato MC, Carolina B, Zuccolotti R, Micheline D. Effect of thermocycling on hardness, absorption, solubility and color change of soft liners. Gerontology 2010;29(2):e215-9. https://doi.org/10.1111/j.1741-2358.2010.00447.x PMid:21083743

14. Hermann C, Mesquita MF, Consani RL, Henriques GE. The effect of aging by thermal cycling and mechanical brushing on resilient denture liner hardness and roughness. J Prosthodont. 2008;17(4):318-22. https://doi. org/10.1111/j.1532-849x.2007.00293.x PMid: 18266656

15. Goiato MC, Zucolotti BC, dos Santos DM, Moreno A, AlvesRezende MC. Effects of thermocycling on mechanical properties of soft lining materials. Acta Odontol Latinoam. 2009;22:227-232.

16. Mainieri VC, Beck J, Oshima HM, Hirakata LM, Shinkai RS Surface changes in denture soft liners with and without sealer coating following abrasion with mechanical brushing. Gerodontology. 2011;28(2):146-51. https://doi. org/10.1111/j.1741-2358.2010.00375.x PMid:21054504

17. Malmström HS, Mehta N, Sanchez R, Moss ME. The effect of two different coatings on the surface integrity and softness of a tissue conditioner. J Prosthet Dent. 2002;87(2):153-7. https:// doi.org/10.1067/mpr.2002.121407

PMid: 11854670

18. Raval HJ, Mahajan N, Naveen YG, Sethuraman R. Athree month comparative evaluation of the effect of different surface treatment agents on the surface integrity and softness of acrylic based soft liner: An in vivo study. J Clin Diagn Res. 2017;11(9):88-91. https://doi.org/10.7860/jcdr/2017/28604.10680 PMid:29207842

19. Ebadian B, Navarchian AH, Sedighipour L. The effect of surface coating on softness of two kinds of tissue. Dent Res J (Isfahan). 2006;3(1):1-6.

20. Hristov I, Slavchev D, Yankov S, Chuchulska B, Zlatev S. Influence of different ways of treatment on hardness of soft relining materials. Int J Sci Res. 2017;6:1769-72. https://doi. org/10.21275/art20175562

21. Kiat-Amnuay S, Gettleman L, Mekayarajjananonth $T$, Khan Z, Goldsmith LJ. The influence of water storage on durometer hardness of 5 soft denture liners over time. J Prosthodont. 2005;14(1):19-24. https://doi. org/10.1111/j.1532-849x.2005.00002.x

PMid:15733131 